\title{
Alliance motivations, control mechanisms and alliance performance: Evidence from China
}

\author{
(C) Higher Education Press and Springer-Verlag 2009
}

\begin{abstract}
Strategic alliance can aid firms to build and sustain their competitive advantages. Firms set up strategic alliance mainly for two purposes: resource acquisition and capability learning. Formal control and social control are two widely adopted control mechanisms to secure the effectiveness of strategic alliance. In this study, we construct a model to analyze the choice of control mechanisms based on alliance motivations and the influence of control mechanisms on alliance performance. Based on a survey of 607 Chinese firms, we find that when resource acquisition is the key motivation behind alliance, formal control should be enhanced. Whereas when capability learning is the main purpose of alliance, social control becomes a better choice. Furthermore, this research also finds that the impact of both formal control and social control on alliance performance are nonlinear. Suggestions are provided on how to effectively use control mechanisms to attain the purposes of strategic alliance and on how to use control mechanisms to enhance alliance performance.
\end{abstract}

Keywords strategic alliance, resource acquisition, capability learning, control mechanisms, alliance performance

Translated and revised from Nankai guanli pinglun 南开管理评论 (Nankai Business Review), 2007, (5): 4-11

SU Zhongfeng $(\bowtie)$

School of Management, Xi'an Jiaotong University, Xi'an 710049, China

E-mail: sfdc@stu.xjtu.edu.cn

XIE En

School of Management, Xi' an Jiaotong University, Xi'an 710049, China

E-mail: xieen@mail.xjtu.edu.cn

LI Yuan

School of Management, Xi'an Jiaotong University, Xi'an 710049, China

E-mail: liyuan@mail.xjtu.edu.cn 
摘要 企业为了不同的目标 (资源获取和能力学习) 建立战略联盟, 而有效的联盟 控制机制（正式控制和社会控制）是实现目标的重要保证。从企业间战略联盟的动 机出发, 提出了实现不同的联盟目标所应采取的控制方式, 并研究了不同的联盟控 制方式对于联盟绩效的影响。通过中国企业间联盟的数据的实证检验, 发现当资源 获取是联盟的主要动机时, 正式控制应当被增强; 而当能力学习是联盟的主要动机 时, 社会控制则是更好的选择。同时, 还发现正式控制和社会控制对联盟绩效的影 响是非线性的。

关键词 战略联盟, 资源获取, 能力学习, 控制机制, 联盟绩效

\section{Introduction}

In recent years, with the deepening of globalization and rapid development of science and technology, an increasing number of firms have established strategic alliances to cope with environmental uncertainty. The resource-based view considers a firm as a collection of productive resources (Penrose, 1959) and suggests that the valuable, rare, inimitable and non-substitutable resources are the foundation of a firm's competitive advantage (Barney, 1991). When these resources can not be acquired from the market, alliance becomes an institutional arrangement firms use to acquire resources. Thus resource acquisition is an important purpose of strategic alliance. In addition, more firms have realized that high learning capability leads to superior performance. As a result, improvement of capability learning has become another important motivation behind cooperation among different firms (Zhang et al., 2002). Drawing upon this rationale, we suggest that there are at least two important motivations for alliance, namely resource acquisition and capability learning. Resource-oriented or capability-oriented strategic alliances vary greatly in a series of aspects, such as resource exchanges, contract contents and behavior supervision. Consequently, different control mechanisms shall be adopted.

However, there has been little research focusing on the choice of control mechanisms based on different motivations for alliance, which is a serious research gap. In reality, most Chinese firms lack the necessary knowledge for alliance management and risk control, partially due to scarcity of theoretical guidance from the academia. As a result, the failure rate of strategic alliances has remained high. Under such circumstances, exploration of the choice of specific control mechanisms for both tangible-resource-oriented and learning-oriented alliances is believed to have great theoretical and practical significance. 


\section{Concepts}

\subsection{Motivations behind strategic alliance}

Based on the assumptions of heterogeneously distributed resources and imperfect resource mobility, the resource-based view suggests that valuable, rare, inimitable and non-substitutable resources lead to sustainable competitiveness (Barney, 1991). The capability-based view points out those firm resources can be divided into tangible (material) and intangible (knowledge) resources in accordance with a series of criteria, such as whether they can be bought or sold, whether they are tangible or intangible, etc. Amit and Schoemaker (1993) proposed that a significant difference between tangible (material) resource and intangible (knowledge) resource is that the former generates the so-called "Richard Rent", while the latter brings forth "Schumpeter Rent". Dyer (1997) further argued that, similar to non-alliance enterprises, strategic alliance members also create values by means of differentiation of tangible resources and accumulation of intangible knowledge and capability. However, alliance provides a more convenient and efficient approach to this value-creating process. We thus infer that there are two basic motivations behind enterprises' strategic alliance establishment: resource acquisition and capability learning.

\subsubsection{Resource acquisition}

Resource acquisition refers to the fact that firms can obtain tangible resource more effectively through alliance. Tangible resource contains financial assets, equipments, products, services and so on (Hitt and Hoskisson, 1996). They constitute the basis of a firm's production and marketing activities. Besides, high quality and differentiated tangible assets yield substantial profit for firms. However, shortage of resources has always been a bottleneck for many firms due to increasingly fierce market competitions. Firms can not obtain all the resources needed over a limited time span. In addition, a firm's demand for all resources tends to be quite uneven, making it quite uneconomical to deposit all types of resources in advance. Therefore, to ally with other firms and utilize their resources to meet one's own demand becomes a better choice (commonly known as resource outsourcing). As one of the earliest viewpoints explaining the motivations for strategic alliance, the tangible-resources-orientation view has been widely accepted by many researchers. In addition to acquisition of much needed resources, strategic alliance can also improve transaction efficiency by lowering considerably transactional uncertainty and costs. Therefore, strategic alliances have been widely adopted by firms as an effective means of obtaining 
resources.

\subsubsection{Capability learning}

In the era of knowledge-based economy, constant generation and efficient management of knowledge are vital to for firms' value creation. Teece et al. (1997) suggested that the very reason for a firm's existence is to constantly create new knowledge. There are two ways for knowledge acquisition. First, the internal approach, which means a firm develops and accumulates knowledge of its own independently. The limitation of this approach is that it demands huge amount of time and resource. Also, a firm can not acquire all the knowledge needed through the internal approach. Second, the external approach, which obtains knowledge and other resources from outside a firm by means of market transaction, merger and acquisition, and strategic alliance. Knowledge and resources obtained through the external approach mainly include tacit knowledge such as technology, managerial knowledge, and routine procedure. The tacit nature of this knowledge makes them rather difficult to be transferred unilaterally. In addition, organizational border imposes considerable restraints on tacit knowledge transfer, giving rise to high transaction cost in a market. Some firms try to solve the problem of high transaction cost by acquiring or merging other firms possessing the desired capabilities or knowledge. However, the merger and acquisition approach also has obvious disadvantages arisen from limited financial resources or managerial issues. Therefore, to acquire new knowledge from one's allied firms or to create new knowledge in collaboration with one's allies seem to be a better choice.

\subsection{Control mechanisms for strategic alliance}

The two widely adopted control mechanisms for strategic alliance are formal control and social control, with the former mainly contract-based and the latter trust-based.

\subsubsection{Contract-based formal control}

In strategic alliances, contract is an important means to control members' behaviors. By signing formal contracts, the responsibilities and obligations of each member can be explicitly defined. Contracts can also be used to protect agreement-abiding members against possible speculative activities (Dyer, 1997). Two types of market contracts have been used in strategic alliance: classical contract, which clearly defines the rights and obligations of all members, is suitable for transactions and cooperation characterized by simple contents, less specific investment, and environmental certainty. With the increase of the asset 
specificity and environmental uncertainty, it becomes increasingly difficult to make explicitly defined contract. Thus, neoclassical contract has been introduced as a new control mechanism, which is more suitable for quite interdependent, yet still remain independent, alliance members. Neoclassical contract regulates actions alliance members should take to adapt to the environmental changes and highlights the flexibility and adaptability of new strategic alliances.

\subsubsection{Trust-based social control}

Formal control emphasizes the economic nature of strategic alliance and speculation prevention mechanism in transactions among alliance members. However, strategic alliance is also characterized by its social attributes due to the repetitive nature of transactions among alliance members. In other words, certain mutual trust is likely to occur between both parties of transactions, which justify well the trust-based social control mechanism for strategic alliance. Self-enforcement is the key characteristic of social control, which means that the implementation of social control does not need the involvement of a third party (Dyer and Singh, 1998). In comparison with formal control, social control is more suitable for complicated alliances (Dyer, 1997). Uzzi (1997) pointed out that strategic alliances relying on social control have the following characteristics: high level of trust, integrated information communication and joint problem-solving mechanisms.

\subsection{Alliance performance}

Compared with individual firms, the measurement of alliance performance is much more complicated in that strategic alliance involves two or more entities, and each entity has its own performance. In addition, the business goals of each entity may vary greatly. As a result, several key issues are included to evaluate alliance performance, such as evaluation angles and evaluation standards (Geringer and Herbert, 1990). Moreover, long-term performance rather than short-term financial benefit is the main purpose pursued by strategic alliances. The performance of individual firms and performance index for individual firms can not reflect fully the overall performance of a strategic alliance (Mjoen and Tallman, 1997). Generally speaking, performance indexes in extant literature can be divided into objective and subjective ones. The former adopt a series of financial and non-financial indexes to measure alliance performance (Geringer and Herbert, 1990). Though the analytical errors of these objective indexes are comparatively small, they can not, sometimes, well reflect the key issues in measuring alliance performance. The specific contents of subjective indexes vary with different research purpose, mainly including degree of satisfaction among 
alliance members, degree of fulfillment of alliance goal, contribution to the promotion of alliance performance, etc. The advantages of subjective alliance performance indexes lie in their superior and comprehensive description of alliance performance from different aspects while their disadvantages mainly stem from low stability and high fluctuation level due to the potential bias of evaluators.

\section{Hypothesis development}

\subsection{The impact of alliance motivation on control mechanisms}

Resource acquisition emphasizes resource complementarity and reduction of transaction cost, while capability learning highlights transfer and absorption of tacit knowledge. Thus there are significant differences between the two motivations for alliance in terms of transfer channel, task complexity, and transaction cost and risks. Thus, to better achieve the goals of strategic alliance, appropriate control mechanisms shall be chosen carefully to coordinate and restrain alliance members' behaviors.

3.1.1 Choice of control mechanisms of strategic alliances for resource acquisition

Alliances with the motivation for resource acquisition have the following two key characteristics: First, a high degree of routinization of resource transaction. Resource-acquisition-oriented alliances usually involve resource transactions in large quantity. As a result, the contents of transaction contract are usually quite simple and all trade clauses can be stated explicitly (Gencturk and Preet, 1995). At the same time, because the degree of asset specificity is low and occurrence of potential changes during the course of contract execution is rare, formal control mechanism can lower considerably cost of resource exchange among alliance members by regulating explicitly transaction time, price and location. Thus for transaction of tangible resources, formal control mechanism does not necessarily bring forth high contracting costs (Tarun, 1998). In addition, by unambiguously marking down all details of resource exchange in advance, formal control can enhance greatly the efficiency of resource exchange. In contrast, social control does not clearly define procedures of each transaction. Thus parties of resource transactions need to get involved into endless coordination and communication in the event of problems. In this sense, an overemphasis of social control in resource-oriented strategic alliances will lower rather than boost exchange efficiency.

Second, it is easy to measure the behavior and output in resource-oriented 
strategic alliances and to track the type, quality, quantity, price and time of resources being exchanged (Zhang et al., 2002). Formal control can also prevent effectively speculative behaviors from happening by adding in punishment clauses in contract. Thus, formal control can not only guarantee the successful execution of resource exchange, but also keep down effectively the cost of supervision and coordination in a strategic alliance.

Third, formal control provides a more convenient and flexible transaction mechanism of resource exchange for alliance members. Dyer and Singh (1998) pointed out that it takes quite a long time and considerable input for social control to take shape. By comparison, formal control is more cost-effective and flexible, making it a more suitable control mechanism for tangible resource transactions (Tarun, 1998).

Fourth, transactions of tangible resource are usually short and time-bounded. However, the setting-up of social control mechanisms usually takes a long time and great input. Thus the more flexible and cost-effective mechanism of formal control is preferred for tangible resource exchange (Dyer and Singh, 1998). After these analyses, we develop two hypotheses as below:

H1 Resource acquisition is positively related to formal control.

H2 Resource acquisition is negatively related to social control.

3.1.2 Choice of control mechanisms of strategic alliances for knowledge acquisition and capability learning.

Capability learning in alliance is a complicated process: On the one hand, the process involves knowledge exchange among different firms in an alliance; on the other hand, to absorb fully one's partner's knowledge, a firm needs to gain a deeper understanding of the tacit knowledge. Whether a control mechanism can effectively facilitate knowledge transfer in an alliance depends on: 1) Whether the control mechanism could enhance the willingness of alliance members to transfer knowledge; 2) Whether the control mechanism could provide sufficient and effective channels for knowledge transfer.

Therefore, we hold that alliances with the purpose of capability learning should focus more on social control rather than on formal control due to the following three reasons: First, social control mechanisms lead to higher level of mutual trust among alliance members, which in turn boost alliance members' willingness to transfer tacit knowledge within the alliance. In contrast, a higher dependence upon formal control mechanisms tends to denote a low trust among alliance members (Das and Teng, 1998), and vice versa (Dyer and Singh, 1998), especially in the context of Chinese culture. When trust among alliance members is low, potential knowledge senders may be unwilling to transfer their knowledge out of consideration for possible piracy of intellectual property by the knowledge 
receiver or possible leakage of the tacit knowledge to one's rivals (Wang, 2000). Under such circumstances, the transaction cost of knowledge transfer in a strategic alliance will be high and the efficiency of the overall learning capability of alliance will be weakened.

Second, due to the complexity of knowledge transfer among different alliance members, an ideal control mechanism must provide enough information to guarantee the efficiency of knowledge transfer (Leidner, 2001). Compared with formal control, social control is better at transferring more detailed, tacit and integrated information (Uzzi, 1997). Social control encourages partners to solve their problems together and provides more "learning by doing" solutions to existing problems.

Third, being intangible, tacit knowledge is significantly different from tangible asset in that the effective exchange of it can not be guaranteed by making formal contracts: first, knowledge is often deeply embedded in a firm's organizational structure, procedures and personnel. Thus without a deeper understanding of these factors, one can not find out the tacit knowledge in a firm, let alone transfer it effectively; second, price is the key factor underlies formal contracts. However, knowledge transfer in a strategic alliance can not be governed effectively by a price mechanism due to a lack of independent external market for knowledge transactions. In other words, dependence on formal control will decrease substantially the efficiency of knowledge transfer in strategic alliances. Given these assumptions, we develop the following hypotheses:

H3 Capability learning is negatively related to formal control.

H4 Capability learning is positively related to social control.

\subsection{The impact of different control mechanisms on alliance performance}

\subsubsection{The relationship between formal control and alliance performance}

The costs of formal control demonstrate a trend of accelerated growth with the increase of control level mainly due to two reasons: first, there will be higher contract costs; second, supervision cost rockets as the level of formal control increases (Dyer and Singh, 1998). Another shortcoming of formal control is that it lacks necessary flexibility and adaptability (Lovett et al., 1991). In other words, too formally controlled strategic alliances tend to be less able to adapt to environmental changes (Luo, 2002), resulting in decreased efficiency of value creation in strategic alliances. In addition, overemphasis on formal control will hamper communications and interactions among alliance members for all firms will try to abide by the explicitly defined clauses in contracts. As a result, given sudden or dramatic environmental changes occur, it is difficult for formally controlled alliances to adapt promptly to a new environment by reaching consensus among all alliance members. Thus: 
H5 There is an inverse U-shaped relationship between formal control and alliance performance.

\subsubsection{The relationship between social control and alliance performance}

After studying the differences of control mechanisms between Japanese strategic alliances in the automobile industry and their America counterparts, Dyer (1997) found that the performance of Japanese auto firms was far better than that of America. The key reason is that Japanese auto firms set up trust-based alliance with raw materials suppliers. In other words, Japanese automobile strategic alliances adopt social control mechanism. We hence infer that the effectiveness of social control does not decrease with the intensification of social control for the following two reasons: First, there is an inverse relation between social control and its cost. The cost of social control reduces as the level of control increases. Fryxell (2002) indicated that the cost of social control mainly comes from the initial stage of alliance. At this stage, both sides need to spend a large amount of resources and time on communication and coordination to foster goodwill and trust among alliance members. Once such a trust is set up, there will be no need for repetitive negotiation or contract signing. In comparison with formal control, social control does not require rigorous supervision over the cooperation process, leading to considerably lower control cost in the later stages. Second, increase in the level of social control may enhance the efficiency of knowledge transfer and resource combination in an alliance. And firms in a socially controlled alliance learn to look at their cooperation with other alliance members in the long run. For tacit knowledge and other intangible resources, strengthened social control mechanism provides effective communication and transmission channels for both transaction parties. Drawing on the above rationale, we propose the following hypothesis:

H6 The influence of social control on alliance performance does not decrease as social control increases.

Fig.1 shows the conceptal model of this article.

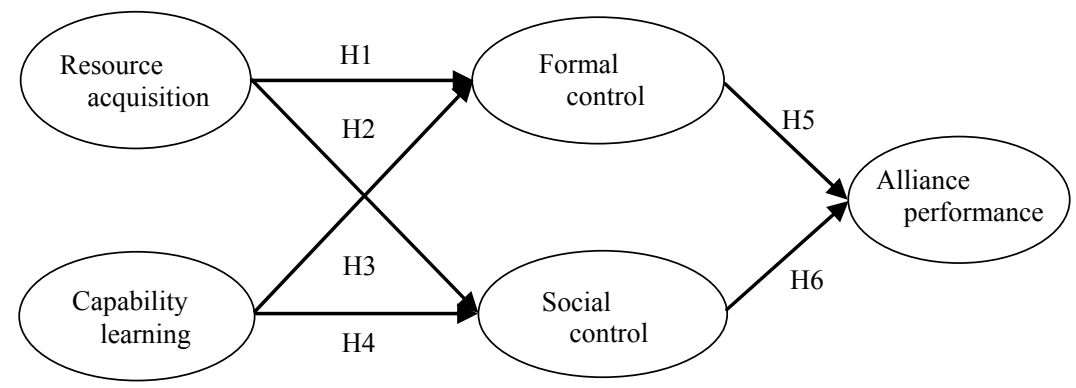

Fig. 1 Conceptal model 


\section{Methods}

\subsection{Sample and data collection}

Hundreds of manufacturing and processing firms from eight different Chinese cities or provinces, namely Shaanxi, Henan, Shanghai, Guangdong, Liaoning, Sichuan, Shandong and Shanxi, participated in our research. Questionnaire was designed to investigate the strategic alliance among these firms. Specifically, we first developed a draft questionnaire based on extant relevant literature and modified it in accordance with the practical conditions these firms faced by consulting extensively with executives of these firms. Then a pilot test was conducted with 15 firms from Shaanxi, Henan and Shandong provinces, whose responses were excluded from the final analysis. The original questionnaire was revised using the feedback from the pilot study and the sample frames provided by the Economy Commerce Committee (ECC, a special governmental department for supervision and administration of national economy) of the above eight city and provinces. 850 enterprises from manufacturing and processing industries were finally chosen as the samples. The final survey was conducted in 2002 with face-to-face method, and most responses were received in that summer. The time frame of 1997 to 2001 was chosen because significant restructuring activities occurred during this period.

The following principles were followed when selecting the samples: 1) Questionnaires shall be filled in by CEOs on the spot with guidance from investigators; 2) Questionnaires with more than 5\% missing answers were regarded as invalid; 3) Respondents were required to answer the questionnaire according to their first reactions; and 4) Questionnaires with consecutive identical answers were considered invalid Out of the 850 firms investigated, a total of 607 copies of questionnaires were collected, with 585 valid copies. Specifically, the return rate was $71.41 \%$ (607 out of 850 ) and the valid response rate was $96.38 \%$ ( 585 out of 607 ). Considering the fact that the questionnaires were filled in by CEOs or their designees, both the return rate and valid response rate were quite satisfactory.

Common problems concerning such a survey methodology is non-response bias, which is the difference between the answers of respondents and non-respondents. Following Armstrong and Overton's (1977) suggestion of comparing the respondents of different waves for possible non-response bias, we split the final sample into two subgroups according to the dates they had received the questionnaires. T-tests performed on the two groups yielded no statistically significant differences on any demographic characteristics. 


\subsection{Variables and measurements}

As noted, some items were modified in accordance with the specific Chinese cultural context of the study. All constructs were measured by the average of the responses on a 7-point Likert scale ( 1 for very different, 7 for very similar).

\subsubsection{Resource acquisition}

As noted, resource acquisition refers to the attainment of tangible material resources via other alliance members. When measuring the variable of resource acquisition, we took into consideration the importance of different types of tangible resources in a strategic alliance. Extant literature usually divides a firm's tangible assets into financial assets, products, and manufacturing equipments (Hitt et al., 1996). Thus, the measurement of resource acquisition consists of the following three items: a firm chooses to ally with other firms in order to 1) seek financial support from these firms; 2) share its equipments and physical assets; and 3) gain a better access to these firms' products or services.

\subsubsection{Capability learning}

According to existing literature (e.g., Steensma and Lyles, 2000), organizational capability can be, in accordance with a firm's main business activities, divided into internal managerial ability, technological ability, ability for market development and marketing, and operational ability. Based on this classification, indexes for measuring capability learning in this study refers to: a firm chooses to participate in an alliance due to the following reasons: 1) To learn advanced technological ability from its allies; 2) To enhance its critical capabilities with the aid from other alliance members; 3) To learn new capability of new product or service development from its allies; and 4) To learn how to cultivate and explore new markets from its allies.

\subsubsection{Formal control}

As above, in formally controlled alliances, formal contracts are usually signed to guarantee the execution of contracts. Thus when measuring the importance of formal control in a given alliance, we need to find out how much each alliance member emphasizes these formal contracts and the importance of supervision over the execution of these contracts. Drawing on Dyer and Singh's (1998) measurement of formal control, we divided the construct of formal control into the following items: 1) We monitor our partner's behaviors during the process of 
cooperation; 2) Only after all details are explicitly defined in formal contracts, will we start cooperate with our allies; 3) We both believe that formal contracts are the most effective tools to monitor the behaviors of both parties; 4) We are inclined to clearly explain all the details in contracts.

\subsubsection{Social control}

Social control refers to the adoption of trust, social relationship and reputation mechanism to indirectly regulate and supervise behaviors of all alliance members. Based on Uzzi's (1997) summary of the main characteristics of socially controlled strategic alliances and relevant work of Geringer and Herbert (1990), we used the following items to measure social control in a strategic alliance: 1) Alliance members use informal channels such as personnel contact, small seminars, etc., to communicate with one another; 2) Both parties have reached a consensus on issues over cooperation goals and prospects; 3) Both parties are encouraged to further expand the scope of their cooperation; 4) The sharing of the information, resources and ability is encouraged within the alliance.

\subsubsection{Alliance performance}

Alliance performance refers to the degree of achievement of preset alliance goals. Financial indexes have been widely adopted in extant literature to measure indirectly performance of strategic alliances. However, this method has several problems: first, progress in financial performance of any individual firm may not necessarily be brought forward by the success of an alliance; second, many alliances may sacrifice short-term profits for long-term gains. Therefore, based on Geringer and Herbert's (1990) relevant study, we measured an alliance's performance by scaling its impact on member firms' competitiveness. The four items used include: 1) We are satisfied with the cooperation achievement of this alliance; 2) The cooperation in this alliance is sound and satisfactory; 3) We have expanded our market share through cooperation with other alliance members; 4) Our competitiveness has been enhanced by cooperating with other alliance members.

\subsubsection{Control variables}

Firm size has an influence on alliance performance, thus, firm size is taken as a control variable in this study. It is measured by the number of employees. In addition, compensation intensity also has an impact on alliance performance, which is used as the other control variable. The measurement of compensation intensity is in accordance with the research of Grewal and Tansuhaj (2001). 


\subsection{Reliability analysis}

Composite reliability assesses the inter-item consistency, which is operationalized by using the internal consistency method estimated by Cronbach's alpha. Typically, reliability coefficients of 0.70 or above are considered adequate (Nunnally, 1978). As can be seen from Table 1, the Cronbach's alpha values of all factors are above 0.70 , showing that the theoretical constructs exhibit good psychometric properties.

Table 1 Variables, measurement items and their respective Coefficient Alphas

\begin{tabular}{|c|c|c|c|}
\hline Variable & Items & Alpha & Loading \\
\hline \multirow{3}{*}{$\begin{array}{l}\text { Resource } \\
\text { acquisition }\end{array}$} & To seek financial support from our allied firms & \multirow{3}{*}{0.7411} & 0.7172 \\
\hline & To share our allies' equipments and physical assets & & 0.8680 \\
\hline & To gain a better access to our allies' products or services & & 0.5934 \\
\hline \multirow{4}{*}{$\begin{array}{r}\text { Capability } \\
\text { learning }\end{array}$} & To learn advanced technological ability from our allies & \multirow{4}{*}{0.9243} & 0.8998 \\
\hline & To enhance our critical capabilities with help from our allies & & 0.9036 \\
\hline & $\begin{array}{l}\text { To learn the ability of developing new products and } \\
\text { service from our allies }\end{array}$ & & 0.8905 \\
\hline & $\begin{array}{l}\text { To learn how to cultivate and explore new markets from } \\
\text { our allies }\end{array}$ & & 0.9175 \\
\hline \multirow[t]{4}{*}{ Formal control } & $\begin{array}{l}\text { We monitor our partner's behaviors during the process of } \\
\text { cooperation }\end{array}$ & \multirow{4}{*}{0.7978} & 0.6430 \\
\hline & $\begin{array}{l}\text { Only after all details are explicitly defined in formal } \\
\text { contracts, will we start cooperating with our allies }\end{array}$ & & 0.8705 \\
\hline & $\begin{array}{l}\text { We both believe that formal contracts are the most } \\
\text { effective means to monitor the behaviors of both parties }\end{array}$ & & 0.8344 \\
\hline & $\begin{array}{l}\text { We are inclined to clearly explain all the details in contract } \\
\text { contracts }\end{array}$ & & 0.8224 \\
\hline \multirow[t]{4}{*}{ Social control } & $\begin{array}{l}\text { Alliance members use informal channels such as personnel } \\
\text { contact, small seminars, etc., to communicate with one } \\
\text { another }\end{array}$ & \multirow{4}{*}{0.7922} & 0.6692 \\
\hline & $\begin{array}{l}\text { Both parties have reached a consensus on issues over } \\
\text { cooperation goals and prospects }\end{array}$ & & 0.8428 \\
\hline & $\begin{array}{l}\text { Both parties are encouraged to further expand the scope of } \\
\text { their cooperation }\end{array}$ & & 0.8176 \\
\hline & $\begin{array}{l}\text { Sharing of the information, resources and ability is } \\
\text { encouraged within the alliance }\end{array}$ & & 0.8183 \\
\hline \multirow{4}{*}{$\begin{array}{l}\text { Alliance } \\
\text { performance }\end{array}$} & We are satisfied with the cooperation achievement of this alliance & \multirow{4}{*}{0.8308} & 0.7837 \\
\hline & The cooperation in this alliance is sound and satisfactory & & 0.8842 \\
\hline & $\begin{array}{l}\text { We have expanded our market share through cooperation } \\
\text { with other alliance members }\end{array}$ & & 0.8540 \\
\hline & $\begin{array}{l}\text { Our competitiveness has been enhanced by cooperating } \\
\text { with other alliance members }\end{array}$ & & 0.8780 \\
\hline
\end{tabular}


Construct validity is the extent to which items on a scale measure the abstract or theoretical construct (Churchill, 1979). The testing of construct validity concentrates not only on discovering whether an item loads significantly on the factors it is measuring, but also on ensuring that it measures no other factors. A loading of 0.7 indicates that about one-half of the item's variance (the squared loading) can be attributed to the construct; thus, 0.7 is the suggested minimum level for item loadings on an established scale (Fornell and Larker, 1981). Nunnally (1978) stated that permissible alpha values could be slightly low $(>0.60)$ for newer scales. Out of the above 19 items, 3 are below 0.7, two of which are over 0.6 , and only one is below 0.6 but over 0.55 . These results show that there are statistically significant relationships among the items and constructs and the reliability of each item is acceptable.

\subsection{Analyses and results}

Subjective measurement method was adopted in this article to explore the relationship among alliance motivations, control mechanisms, and alliance performance, making structural equation model a better method to analyze the influence mechanism among these variables. Thus, the first four hypotheses are tested by using the path analysis method in a structure equation model. The analysis results are reported in Table 2.

Table 2 Results of choice of different control mechanisms

\begin{tabular}{|c|c|c|c|}
\hline Path & Coefficient & Path & Coefficient \\
\hline $\begin{array}{l}\text { Resource acquisition } \rightarrow \\
\text { Formal control }\end{array}$ & $0.1850 * *$ & $\begin{array}{l}\text { Capability learning } \rightarrow \text { Formal } \\
\text { control }\end{array}$ & $-0.1410 * * *$ \\
\hline $\begin{array}{l}\text { Resource acquisition } \rightarrow \\
\text { Social control } \\
\end{array}$ & $-0.1302 *$ & $\begin{array}{l}\text { Capability learning } \rightarrow \text { Social } \\
\text { control }\end{array}$ & $0.1714 * * *$ \\
\hline
\end{tabular}

Note: $*$ indicates significant at $0.05 ; * *$ indicates significant at $0.01, * * *$ indicates significant at 0.001 .

The testing results of Hypothesis 5 and 6, which argue that formal control and social control exert no-linear influences on alliance performance, are listed in Table 3.

Table 3 Impact of different control mechanisms on alliance performance

\begin{tabular}{ccccccccc}
\hline $\begin{array}{c}\text { Formal } \\
\text { control (FC) }\end{array}$ & $\begin{array}{c}\text { Social control } \\
(\mathrm{SC})\end{array}$ & FC2 & SC2 & Size & $\begin{array}{c}\text { Competition } \\
\text { intensity }\end{array}$ & $\begin{array}{c}\text { Chi- } \\
\text { square }\end{array}$ & $\begin{array}{c}P \text { - } \\
\text { Value }\end{array}$ & Adjusted- $R^{2}$ \\
\hline $0.148^{*}$ & $0.368^{* * *}$ & $-0.110^{*}$ & $-0.044^{+}$ & 0.027 & 0.065 & 197.518 & 0.000 & 0.233 \\
\hline
\end{tabular}

Note: * indicates significant at $0.05 ; * *$ indicates significant at $0.01, * * *$ indicates significant at $0.001{ }^{+}$indicates significant at 0.1 . 


\section{Discussion}

$\mathrm{H} 1$ and $\mathrm{H} 2$ discuss the relationships between resource acquisition and the choice of control mechanisms. Empirical results suggest that resource acquisition exerts a positive impact on formal control and a negative one on social control. With the increase of alliance's complexity, more scholars have started to emphasize the importance of social control. Comparatively speaking, the role of formal control has been neglected. In this study, we find that different control mechanisms should be used to suit different alliance motivations: For the alliance with the purpose of resource acquisition, formal control has proved to be a better control mechanism than social control.

The relationships between capability learning and the choice of control mechanisms are discussed in $\mathrm{H} 3$ and $\mathrm{H} 4$. Results indicate that capability learning has a negative impact on formal control and a positive one on social control. Thus, the stronger the motivation for capability learning, the higher level of social control should be applied. This is consistent with the perspective that knowledge transfer is very difficult to realize through the use of contract. Our results also contribute to the theoretical frame of Das and Teng (1998), which suggests that the choice of alliance control mechanisms depends on the measurability of procedure and output: When the measurability of both procedure and output is high, formal control is a better choice; when the measurability of both procedure and output is low, social control should be preferred; when the measurability of both procedure and output is at the medium level, we need to use the two kinds of control mechanisms combinedly. In our model, the measurability of procedure and output of resource acquisition is high, which justifies well the adoption of formal control mechanism; while that of capability learning is low, so we choose social control.

Our results also indicate that there is an inverse U-shaped relationship between formal control and alliance performance, which supports H5. Thus, there is an optimum level of formal control. This result is consistent with the findings of Luo (2002). H6 discusses the relationship between social control and alliance performance. It is found that social control also has an adverse effect on alliance performance, thus H6 is not supported. Although previous research has argued that the relationship between social control and alliance performance may be inverse U shaped (Uzzi, 1997), our empirical findings do not support such a perspective. Our research is the first one to find an inverse $U$ shaped relation between social control and alliance performance. We deem that the diversity in business traditions between China and Western economies may partially lead to this result. Chinese business tradition emphasizes the critical roles of social control on the stability of alliance, Thus Chinese alliance may tend to 
over-emphasize the use of social control, which probably makes it more difficult for alliance members to absorb information, resource, and knowledge from outside the alliance. As a result, the whole alliance's performance is hurt (Uzzi, 1997).

\section{Conclusions}

We find in this study that alliance motivations play critical roles in the choice of alliance control mechanisms. When resource acquisition is the main purpose of alliance, formal control is more effective than social control, while when the motivation behind alliance is capability learning, social control should be adopted. Moreover, this study also tests the influences of control mechanisms on alliance performance. Results indicate that the impacts of both formal control and social control on alliance performance are non-linear. These findings can help China's strategic alliance to choose more suitable control mechanisms, raise the efficiencies of alliance control mechanisms, and further enhance alliance performance.

Acknowledgements This work is supported by the National Natural Science Foundation of China (No. 70472039, 70571063).

\section{References}

Amit R, Schoemaker P J H (1993). Strategic assets and organizational rent. Strategic Management Journal, 14(1): 33-46

Armstrong J S, Overton T (1997). Estimating non-response bias in mail surveys. Journal of Marketing Research, 14: 396-402

Barney J B (1991). Firm resources and sustained competitive advantage. Journal of Management, 17: 99-120

Churchill G A (1979). A paradigm for developing better measures of marketing constructs. Journal of Marketing Research, 16: 64-73

Das T K, Teng B S (1998). Resource and risk management in strategic alliance making process. Journal of Management, 24(1): 21-42

Dyer J H (1997). Effective inter-firm collaboration: How firms minimize transaction costs and maximize transaction value. Strategic Management Journal, 18: 535-556

Dyer J, Singh H (1998). The relational view: Cooperative strategy and sources of inter-organizational competitive advantage. Academy of Management Review, 23(4): $600-679$

Fornell C, Larcker D F (1981). Evaluating structural equation models with unobservable variables and measurement error. Journal of Marketing Research, 18: 39-50

Fryxell G E, Dooley R S, Vryza M(2002). After the ink dries: The interaction of trust and control in U.S. based international joint ventures. Journal of Management Studies, 39(6): 
865-886

Gencturk E F, Preet S A (1995). The use of process and output controls in foreign markets. Journal of International Business Studies, 26: 755-786

Geringer J M, Herbert L H (1990). Measuring performance of international joint ventures. Journal of International Business Studies, 3: 249-265

Grewal R, Tansuhaj P (2001). Building organizational capabilities for managing economic crisis: The role of market orientation and strategic flexibility. Journal of Marketing, 65 : $67-80$

Hitt M, Dacin M, Tina L E, Arregle J, Borza A (1996). Partner selection in emerging and developed market contexts: Resource-based and organizational learning perspectives. Academy of Management Journal, 43: 449-467

Hitt M A, Hoskisson R E (1996). The market for corporate control and firm innovation. Academy of Management Journal, 39(5): 1084-1119

Leidner A (2001). Knowledge management and knowledge management system: Conceptual foundations and research issues. MIS Quarterly, 25(1): 107-132

Lovett S, Simmons L, Kali R (1991). Guanxi versus the market: Ethics and efficiency. Journal of International Business Studies, 30(2): 231-248

Luo Yadong (2002). Contract, cooperation, and performance in international joint ventures. Strategic Management Journal, 23: 903-919

Mjoen H, Tallman S (1997) Control and performance in international joint ventures. Organization Science, 18(3): 257-274

Nunnally J C (1978). Psychometric Theory (2nd edition). New York: McGraw-Hill

Penrose E T (1959). The Theory of the Growth of the Firm. New York: John Wiley

Steensma H K, Lyles M A (2000). Explaining IJV survival in a transitional economy through social exchange and knowledge based perspective. Strategic Management Journal, 21(8): $831-852$

Tarun K (1998). The dynamics of learning alliances: Competition, cooperation, and relative scope. Strategic Management Journal, 19: 193-210

Teece D J, Pisano G, Shuen A (1997). Dynamic capabilities and strategic management. Strategic Management Journal, 18: 509-533

Uzzi B (1997). Social structure and competition in inter-firm networks: The paradox of embeddedness. Administrative Science Quarterly, 42(1): 37-69

王蓄 (Wang Qiang) (2000). 战略联盟内部的相互信任及其建立机制 (Mutual trust and its mechanism within strategic alliance). 南开管理评论, (3)

张延峰, 刘益, 李垣 (Zhang Yanfeng, Liu Yi, Li Yuan) (2002). 国内外战略联盟理论研究评论 (A review of domestic and foreign studies on strategic alliance theory). 南开管理评论, (2) 